\title{
Factors associated with HIV testing and receiving results during antenatal care in Tanzania
}

\author{
Innocent Semali ${ }^{1}$, Damian Jeremia Damian ${ }^{2}$, Happiness Pius Saronga $^{1}$ and \\ Deogratius Malamsha ${ }^{3}$ \\ ${ }^{1}$ Muhimbili University of Health and Allied Sciences, Kilimanjaro Christian Medical University College \\ $(\mathrm{KCMUCO})^{2}$ and ${ }^{3}$ National Bureau of Statistics
}

\begin{abstract}
Mother to child transmission of HIV (MTCT) control goal is achievable when all pregnant mothers test for HIV and collect the results enabling timely eligibility and access to anti-retroviral therapy (ART). This study aimed to determine factors associated with uptake of HIV testing during antenatal care in Tanzania. Using 2011-2012 Tanzania HIV and Malaria Indicator Survey data, 3555 women who attended antenatal clinic and delivered in the last two years were analyzed. One was considered HIV tested if she took HIV test and collected results. Bivariate and multivariate analysis was done using STATA version 12.

High proportion $(76 \%)$ tested for HIV during antenatal care, factors significantly associated $(p<0.05)$ with testing included receiving information on HIV testing during antenatal care, age, education and wealth. Proportion taking HIV test was high, prevention of MTCT (PMTCT) strategies should focus on increasing information on testing during antenatal care (ANC), targeting the young, less educated and poor.
\end{abstract}

Keywords: HIV; MTCT; PMTCT; AN C; Tanzania

\section{Résumé}

L'objectif de lutte contre la transmission mère- enfant (TME) du VIH est réalisable lorsque tous les dépistages du VIH de mères enceintes et le recueilli des résultats lors des soins prénataux permettent à l'accès aux traitements antirétroviraux (TAR). Cette étude vise à déterminer les facteurs associés au dépistage du VIH lors des soins prénataux en Tanzanie. En utilisant les données de l'enquête sur l'indicateur du paludisme et du VIH en Tanzanie de 2011-2012; 3555 femmes qui ont assisté à la clinique prénatale et ont mis au monde dans les deux dernières années ont été sujets d'analyses. Une personne était considérée dépistée pour le VIH si elle a fait le test du VIH et les résultats ont été recueillis. Les analyses bi-variée et multi-variée ont été effectuées en utilisant la version STATA 12. Proportion élevée (76\%) ont fait le dépistage pour le VIH lors des soins prénataux, les facteurs importants $(p<0,05)$ associés au test y compris : recevoir des informations sur le dépistage du VIH lors des soins prénataux, l'âge, l'éducation et la richesse. La proportion de personnes dépistées pour le VIH était élevée; des stratégies de prévention TME (TPME) devraient se concentrer sur l'intensification des l'information sur le dépistage au cours de soins prénataux, ciblant des jeunes, les moins instruits et les pauvres.

Mots clé: VIH;TME; TPME; SPN; Tanzanie 


\section{Introduction}

Globally there are 37 million people living with HIV, among which 3.7 million are children (Murray, Vos et al. 2012). Most of the HIV burden is located in Sub-Saharan Africa though it is home to only $12 \%$ of the global population (Lozano, N aghavi et al. 2012). Furthermore the prevalence of HIV is higher among women compared to men (van Tienen, van der Loeff et al. 2010). Annually about 400,000 children are being infected with HIV of whom $90 \%$ $(300,000)$ are due to mother to child transmission of HIV (MTCT) (Tudor Car, van-Velthoven et al. 2011).

In Tanzania it is estimated that about 2.4 million people are living with HIV and AIDS of whom 660,000 are eligible for ART (Ministry of Health and Social Welfare 2012). Currently HIV prevalence among adults $15-49$ years is $5.1 \%$ which is higher among women $(6.2 \%)$ compared to men $(3.8 \%)$ (Tanzania Commission for AIDS (TACAIDS), Zanzibar AIDS Commission (ZAC) et al. 2013). HIV prevalence among pregnant women is also reported to be slightly higher $(6.9 \%)$ compared to the general population. It is also estimated that annually about 119,000 pregnant women are HIV positive and whose risk of mother to child transmission of HIV (MTCT) is estimated at $25 \%$ annually without intervention. Thus annually 43,050 HIV infected children are born in Tanzania despite the existence of effective intervention to prevent MTCT of HIV (PMTCT) (Joshi, Kadri et al. 2010; Nyandiko, Otieno-N yunya et al. 2010; Tanzania Commission for AIDS (TACAIDS), Zanzibar AIDS Commission (ZAC) et al. 2013; Tubiana, Mandelbrot et al. 2013). Thus this study aimed at determining the current proportion of voluntary HIV testing uptake and collections of the test results among pregnant women as a important component of PMTCT practice in Tanzania.

\section{Literature review}

PMTCT has four prongs namely; 1) Primary prevention of HIV for women of childbearing age; 2) Prevention of unintended pregnancies among women living with HIV; 3) Prevention of vertical transmission of HIV from mother to child; and 4) HIV treatment, care and support for women living with HIV, their children and other family members (Ezegbe and Stephenson 2012). The third prong constitutes HIV testing and counseling, antiretroviral therapy for preventing mother-to-child transmission and infant feeding, counseling and support. Though there is a wide coverage of care treatment centers to provide PMTCT the unmet ART need remains at 48\% (Lyons, Mushavi et al. 2012).

Global and National responses focused at adoption of comprehensive PMTCT strategies at national level and enhanced capacity of the health care systems to increase coverage in order to achieve the goal that all eligible children will access ART by 2015 (Chi, Adler et al. 2012; Paredes, Marconi et al. 2013). Tanzania response included adoption of PMTCT guiding goal to eliminate new HIV pediatric infections and keep mothers alive through improved maternal, newborn and child health and survival programs by 2015. However, access to comprehensive PMTCT is contingent upon taking HIV test during antenatal period and collecting results followed with access to PMTCT interventions (Watson-Jones, Balira et al. 2012; Wettstein, Mugglin et al. 2012).

Pregnant mothers before accessing PMTCT have to consider stress arising from disclosure of their HIV sero-status as a result of associated stigma and discrimination. As a result of the existing community stigma, pregnant mothers are less likely to accept HIV counseling and testing and thus give birth without benefits of PMTCT (Turan, Hatcher et al.; Turan, Miller et al. 2008). Widespread stigma and discrimination has contributed significantly to thwart the national efforts to roll out PMTCT services to the most needy (Shetty, Marangwanda et al. 2008; Tudor Car, Van Velthoven et al. 2012). Factors observed to mitigate stigma and discrimination included education as persons with better education are less likely to be negatively affected by stigma and discrimination (O w and Lee 2012) (Veloso, Bastos et al. 2010). O vercoming stigma and discrimination is thus an important component of the ongoing strategies to increase PMTCT coverage in order to achieve national coverage goals.

Additional factors influencing counseling, testing and collection of results includes social demographic characteristics, age, marital status, gender relations, place of residence, wellbeing and wealth (Cherutich, Kaiser et al. 2012) (Ettenger, Barnighausen et al. 2013). Thus knowing which factors negatively affect access to PMTCT would facilitate adoption of interventions that will increase access to PMTCT in a given geographical cultural context which will facilitate achieving the PMTCT goals.

It is thus envisaged that by 2015 more than $90 \%$ of pregnant mothers and children should be accessing HIV test and subsequently access to ART. Whereas it is only two years away from 2015 and 
given new policy and strategies to scale-up access to PMTCT it is important to understand the current, HIV testing and collection of results among pregnant women. Such results will enable meeting the 2015 goal of access to ART for all eligible children, all mothers have to access HIV testing, care and ART. Hence, the aim of this study was to determine HIV testing and associated factors among pregnant women in the contexts of PMTCT in Tanzania.

\section{Methods}

Data source

This study used the 2011-2012 Tanzania HIV/AIDS and Malaria Indicator Survey (THMIS) individual dataset. THMIS is a population based nationally representative cross-sectional survey, employing a multi-stage stratified sampling. The sampling design and sampling selection process was based on the 2002 Tanzania Population and Household Census which is presented in detail in the THIMS final report (Tanzania Commission for AIDS (TACAIDS), Zanzibar AIDS Commission (ZAC) et al. 2013).

Women and men aged 15-49 years who were in the selected households the night before the survey were interviewed using standard questionnaires adapted to the Tanzanian context. A total of 10,967 women responded, however the study was restricted to the 3555 that gave birth in the past 24 months from the date of interview. Appropriate weights were generated and assigned relevant variables for use during analysis to account for the design effect.

Variables

The dependent variable was defined as tested for HIV if the pregnant woman tested for HIV and collected the results during antenatal care in the last 24 months. In order to run the logistic analysis, if a mother had taken the HIV test the variable HIV testing was labeled "Yes" and coded " 1 " and if she had not tested the variable was labeled "No" and was coded " 0 "..

Independent variables as extracted from THIMS included woman's background characteristics including age, marital status, and education level, place of residence, sexual behavior and household wealth quintile. For the purpose of this analysis sexual behavior was defined as the total number of sexual partners a woman has had in her lifetime which was categorized into two groups, 1 partner and 2 or more partners.
Independent variables also included characteristics of the health facility a woman attended during $A N C$, which included ownership, type and whether the facility offered the woman information on mother to child transmission of HIV (MTCT). Health facility type was categorized into hospital, health centre and dispensary.

0 ther independent variables included woman's comprehensive knowledge on MTCT and having stigmatizing attitude towards HIV. MTCT comprehensive knowledge was defined as having knowledge on vertical transmission dynamics of HIV which included knowledge that HIV can be transmitted from a mother to her baby during pregnancy, delivery and breastfeeding, and special drugs are there to reduce the HIV transmission risk. Stigmatizing attitude was considered present if a woman expressed negative attitude towards; buying fresh vegetables from a shopkeeper or vendor having the AIDS virus, disclosure of the HIV-positive status of a family member, care for a family member sick with the AIDS virus in their own home, allowing a female teacher with the AIDS virus to continue teaching and allowing a male teacher with the AIDS virus to continue teaching.

Statistical analysis

Data was analyzed using STATA version 12, all analysis used weights and swy codes to account for the design effect for each variable (StataCorp. 2009). Bivariate unadjusted logistic regression analysis was done to calculate the crude odds ratio $(O R)$ of the association between the dependent and independent variables. In the analysis each variable was weighted to account for the design effect and association was significant if the $p$-value was less than 0.05 . Furthermore, multivariate logistic analysis was done to calculate the adjusted odds ratios (AOR), 95\% Cl and p-value to determine variables independently associated with testing for HIV among pregnant women attending antenatal clinic.

Ethical clearance

Permission to access and use THMIS data was obtained from MEASURE DHS through the online registration system. Prior, ethical approval for the THMIS survey was granted from the Tanzania's $\mathrm{N}$ ational Institute for Medical Research (N IMR), the Zanzibar Medical Ethics and Research Committee (ZAMREC), the Institutional Review Board of ICF International, and the Centers for Disease Control and Prevention in Atlanta, while each respondent participating had granted consent to be a participant. 


\section{Results}

General characteristics of the study subjects

A total of 3,555 women who attended antenatal clinic (ANC) and gave birth in the past two years prior to THMIS 2011/2012 survey were included in this analysis. The majority were currently married $(82.9 \%)$; with primary education $(65.7 \%)$ and resided in the rural areas (82.1\%) see Table 1. In

addition most $(82.7 \%)$ resided in male headed households, had received information on HIV testing during ANC (57.3\%) and had two or more lifetime sexual partners $(52.8 \%)$. A high proportion $(71.9 \%)$ did not have stigmatizing attitude towards HIV, did not have comprehensive knowledge of MTCT $(54.6 \%)$ and tested for HIV as part of ANC and collected results $(76.1 \%)$. 
Table 1: General characteristics of the study subjects $(n=3555)$.

\begin{tabular}{|c|c|c|c|}
\hline Characteristics & $\begin{array}{l}\text { Unweighted } \\
\text { Percent }\end{array}$ & $\begin{array}{l}\text { Weighted } \\
\text { Percent }\end{array}$ & $\begin{array}{l}\text { Weighted } \\
\text { Total }\end{array}$ \\
\hline \multicolumn{4}{|l|}{ Age of woman } \\
\hline $15-24$ & 36.1 & 37.4 & 1328 \\
\hline $25-34$ & 43.2 & 42.6 & 1515 \\
\hline $35+$ & 20.7 & 20.0 & 712 \\
\hline \multicolumn{4}{|l|}{ Marital status } \\
\hline N ever married & 7.9 & 8.6 & 308 \\
\hline Currently married & 83.8 & 82.9 & 2947 \\
\hline Formerly married & 8.3 & 8.4 & 299 \\
\hline \multicolumn{4}{|l|}{ Education } \\
\hline No education & 23.2 & 23.4 & 832 \\
\hline Primary & 63.5 & 65.7 & 2335 \\
\hline Secondary + & 13.3 & 10.9 & 388 \\
\hline \multicolumn{4}{|l|}{ Residence } \\
\hline Urban & 15.2 & 17.9 & 637 \\
\hline Rural & 84.8 & 82.1 & 2918 \\
\hline \multicolumn{4}{|l|}{ Wealth } \\
\hline Poorest & 21.3 & 22.4 & 799 \\
\hline Poorer & 22.4 & 22.8 & 811 \\
\hline Middle & 21.3 & 19.5 & 693 \\
\hline Richer & 20.1 & 19.1 & 679 \\
\hline Richest & 14.9 & 16.2 & 575 \\
\hline \multicolumn{4}{|c|}{ Sex of head of household } \\
\hline Male & 83.5 & 82.7 & 2940 \\
\hline Female & 16.5 & 17.3 & 615 \\
\hline \multicolumn{4}{|c|}{$\begin{array}{l}\text { Received information on HIV testing during } \\
\text { ANC }\end{array}$} \\
\hline No & 42.2 & 42.7 & 1519 \\
\hline Yes & 57.8 & 57.3 & 2036 \\
\hline \multicolumn{4}{|c|}{ Sexual behavior (lifetime sexual partners) } \\
\hline 1 & 50.2 & 47.2 & 1679 \\
\hline $2+$ & 49.8 & 52.8 & 1876 \\
\hline \multicolumn{4}{|c|}{ Stigmatizing attitudes towards HIV } \\
\hline No & 72.9 & 71.9 & 2556 \\
\hline Yes & 27.1 & 28.1 & 999 \\
\hline \multicolumn{4}{|c|}{ Tested HIV as part of ANC and received results } \\
\hline No & 23.5 & 23.9 & 849 \\
\hline Yes & 76.9 & 76.1 & 2706 \\
\hline \multicolumn{4}{|c|}{ Comprehensive knowledge of MTCT } \\
\hline No & 53.8 & 54.6 & 1939 \\
\hline Yes & 46.2 & 45.4 & 1616 \\
\hline \multicolumn{4}{|l|}{ Type of health facility } \\
\hline Hospital & 16.7 & 16.1 & 573 \\
\hline Health centre & 4.1 & 5.1 & 181 \\
\hline Dispensary & 44.9 & 46.1 & 1639 \\
\hline O thers & 34.3 & 32.7 & 1163 \\
\hline Total & 100 & 100 & 3,555 \\
\hline
\end{tabular}

Figure 1 presents the proportion of pregnant women who were offered the HIV test (81\%) and those that tested $(80 \%)$, however the proportion that tested for HIV and collected results was much lower $(76 \%)$. 
$(n=3,555)$

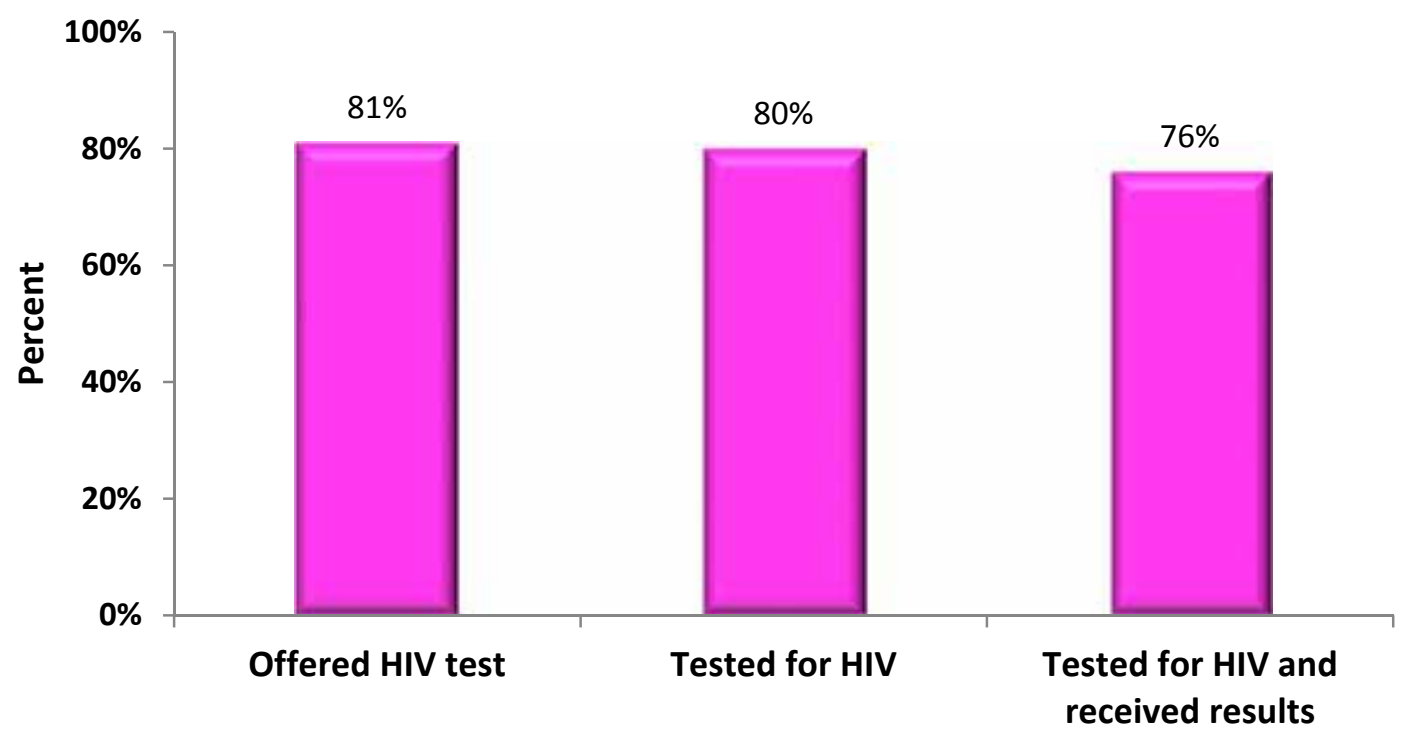

Figure 1: Descriptive summary of ANC MTCT services to women ( $n=3555)$

Bivariate analysis of factors associated with H IV testing during AN C

Women with primary education had more than twice the odds of testing and receiving results during ANC compared to those who had no education (OR=2.43, 95\% Cl 1.76-3.33, $\mathrm{P}<0.001$ ) see Table 2. In addition those who had secondary education or above had five times higher odds of testing and receiving results during $A N C$ compared to those who had no education $(\mathrm{OR}=5.38,95 \% \mathrm{Cl} 3.12$ 9.30, $\mathrm{P}<0.001)$. Women who were living in rural areas had $68 \%$ less odds of testing and receiving results during $A N C$ as compared to those who were living in urban areas during the survey $(O R=0.32$, 95\% Cl 0.18-0.56, $\mathrm{P}<0.001$ ).

Women in the poorer quintile had $51 \%$ higher odds of testing and receiving results compared to those in the poorest quintile $(\mathrm{OR}=1.51,95 \% \mathrm{Cl}$ 1.06-2.15, $\mathrm{P}=0.021$ ). Also those in the middle quintile had more than two times higher odds of testing and receiving results compared to those in the poorest quintile $(\mathrm{OR}=2.30,95 \% \mathrm{CI} 1.59-3.34$, $\mathrm{P}<0.001$ ). Furthermore those in the richer quintile had more than three times higher odds of testing and receiving results as compared to those in the poorest quintile $(\mathrm{OR}=3.16,95 \% \mathrm{Cl}$ 2.29-4.36, $\mathrm{P}<0.001$ ) and those in the richest quintile had more than seven times higher odds of testing and receiving results compared to those in the poorest quintile (OR=7.22, 95\% Cl 3.96-13.17, $\mathrm{P}<0.001$ ).

Women who reported to have received information on HIV testing during ANC had more than seven times higher odds of testing compared to those who did not get such information $(O R=7.34$, 95\% Cl 5.40-9.84, $\mathrm{P}<0.001$ ) see Table 2 . Women who reported to have two or more lifetime sexual partners had $47 \%$ higher odds of testing compared to those who had only one lifetime sexual partner (O $\mathrm{R}=1.47,95 \% \mathrm{Cl} 1.16-1.86, \mathrm{P}=0.002$ ).

Women who did not have stigmatizing attitude towards HIV had two times higher odds of testing and receiving test results compared to those with stigmatizing attitude $(\mathrm{OR}=2.00,95 \% \mathrm{Cl} 1.52-2.63$, $P<0.001)$. However, woman's age, marital status, sex of household head, comprehensive knowledge of MTCT and type of the health facility the woman attended during ANC showed no significant association with HIV testing and receiving results during ANC $(P>0.05)$. 
Table 2: Bivariate analysis of factors associated with HIV testing and receiving test results during AN C $(n=3,555)$.

\begin{tabular}{|c|c|c|c|c|}
\hline Factors & $\mathbf{n}$ & $\begin{array}{l}\text { Tested } \& \\
\text { received results }\end{array}$ & OR $(95 \% \mathrm{CI})$ & P-value \\
\hline \multicolumn{5}{|l|}{ Age of woman } \\
\hline $15-24$ & 1328 & 74.0 & 1 & \\
\hline $25-34$ & 1515 & 77.8 & $1.23(0.99,1.53)$ & 0.062 \\
\hline $35+$ & 712 & 76.5 & $1.14(0.90,1.45)$ & 0.282 \\
\hline \multicolumn{5}{|l|}{ Marital status } \\
\hline $\mathrm{N}$ ever married & 308 & 78.6 & 1 & \\
\hline Currently married & 2947 & 75.6 & $0.84(0.54,1.33)$ & 0.465 \\
\hline Formerly married & 299 & 78.9 & $1.02(0.59,1.77)$ & 0.951 \\
\hline \multicolumn{5}{|l|}{ Education } \\
\hline No education & 832 & 61.2 & 1 & \\
\hline Primary & 2335 & 79.2 & $2.42(1.76,3.33)$ & $<0.001$ \\
\hline Secondary + & 388 & 89.4 & $5.38(3.12,9.30)$ & $<0.001$ \\
\hline \multicolumn{5}{|l|}{ Residence } \\
\hline Urban & 637 & 89.6 & 1 & \\
\hline Rural & 2918 & 73.2 & $0.32(0.18,0.56)$ & $<0.001$ \\
\hline \multicolumn{5}{|l|}{ Wealth } \\
\hline Poorest & 799 & 61.6 & 1 & \\
\hline Poorer & 811 & 70.7 & $1.51(1.06,2.15)$ & 0.021 \\
\hline Middle & 693 & 78.7 & $2.30(1.59,3.34)$ & $<0.001$ \\
\hline Richer & 679 & 83.5 & $3.16(2.29,4.36)$ & $<0.001$ \\
\hline Richest & 575 & 92.0 & $7.22(3.96,13.17)$ & $<0.001$ \\
\hline \multicolumn{5}{|l|}{ Sex of head of household } \\
\hline Male & 2940 & 75.5 & 1 & \\
\hline Female & 615 & 79.0 & $1.22(0.92,1.63)$ & 0.172 \\
\hline \multicolumn{5}{|c|}{$\begin{array}{l}\text { Received information on HIV testing } \\
\text { during AN C }\end{array}$} \\
\hline No & 1519 & 56.7 & 1 & \\
\hline Yes & 2036 & 90.6 & $7.34(5.40,9.84)$ & $<0.001$ \\
\hline $\begin{array}{l}\text { Sexual behavior (lifetime } \\
\text { partners) }\end{array}$ & & & & \\
\hline 1 & 1679 & 72.4 & 1 & \\
\hline $2+$ & 1876 & 79.4 & $1.47(1.16,1.86)$ & 0.002 \\
\hline \multicolumn{5}{|c|}{ Stigmatizing attitudes towards HIV } \\
\hline Yes & 2556 & 72.9 & 1 & $<0.001$ \\
\hline No & 999 & 84.3 & $2.00(1.52,2.63)$ & \\
\hline \multicolumn{5}{|c|}{ Comprehensive knowledge of MTCT } \\
\hline No & 1939 & 68.9 & 1 & \\
\hline Yes & 1616 & 84.8 & $1.22(0.92,1.63)$ & 0.172 \\
\hline \multicolumn{5}{|l|}{ Type of health facility } \\
\hline Hospital & 573 & 97.3 & 1 & \\
\hline Health centre & 181 & 95.4 & $0.58(0.21,1.59)$ & 0.287 \\
\hline Dispensary & 1639 & 94.8 & $0.51(0.25,1.04)$ & 0.065 \\
\hline Others & 1163 & 36.3 & $0.02(0.01,0.03)$ & $<0.001$ \\
\hline \multicolumn{2}{|c|}{$\begin{array}{l}\text { Multivariate logistic regression analysis of factors } \\
\text { associated with HIV testing and receiving results during } \\
\text { ANC. }\end{array}$} & \multicolumn{3}{|c|}{$\begin{array}{l}\text { multivariate analysis also revealed that women in } \\
\text { the poorer quintile had } 63 \% \text { higher odds of testing } \\
\text { and receiving results during ANC as compared to } \\
\text { those who were in the poorest quintile }(O R=1.63 \text {, } \\
95 \% \mathrm{Cl} 1.10-2.40, \mathrm{P}=0.014) \text {. Women in the middle }\end{array}$} \\
\hline
\end{tabular}


quintile had two times higher odds of testing in comparison to those in the poorest quintile $(\mathrm{OR}=2.23,95 \% \mathrm{Cl} 1.47-3.39, \mathrm{P}<0.001)$. Whereas those in the richer quintile had almost three times higher odds of testing and receiving results as compared to those in the poorest quintile $(\mathrm{O} R=2.85,95 \% \mathrm{Cl} 1.88-4.31, \mathrm{P}<0.001)$ and those in the richest quintile remarkably had more than five times higher odds of testing compared to those in the poorest quintile $(\mathrm{OR}=5.30,95 \% \mathrm{Cl} 2.51-11.19$, $P<0.001)$.
Women who reported to have received information on HIV testing during ANC had four times higher odds of testing and receiving results compared to those who did not receive information (OR=4.65, 95\% Cl 3.38-6.42, $\mathrm{P}<0.001) . \mathrm{O}$ dds of testing was about $40 \%$ higher for women aged 35 years and above compared to those less than 25 years (OR $=1.38,95 \% \mathrm{Cl} 1.01-1.88$, $p$-value 0.043 ). Women having secondary education or more almost doubled the odds of testing $(O R=1.8695 \% \mathrm{Cl}$ 1.04-3.30, p-value 0.035) compared to those with no

education.

Table 3: Multivariate analysis of factors associated with HIV testing and receiving test results during ANC $(n=3,555)$.

\begin{tabular}{|c|c|c|c|c|}
\hline Factors & $\begin{array}{l}\text { Weighted } \\
\text { n }\end{array}$ & $\begin{array}{l}\text { Tested \& } \\
\text { received results }\end{array}$ & $\mathrm{AOR}^{\dagger}(95 \% \mathrm{Cl})$ & P-value \\
\hline \multicolumn{5}{|l|}{ Age of woman } \\
\hline $15-24$ & 1328 & 74.0 & 1 & \\
\hline $25-34$ & 1515 & 77.8 & $1.35(0.97,1.87)$ & 0.076 \\
\hline $35+$ & 712 & 76.5 & $1.38(1.01,1.88)$ & 0.043 \\
\hline \multicolumn{5}{|l|}{ Education } \\
\hline No education & 832 & 61.2 & 1 & \\
\hline Primary & 2335 & 79.2 & $1.27(0.94,1.71)$ & 0.118 \\
\hline Secondary + & 388 & 89.4 & $1.86(1.04,3.30)$ & 0.035 \\
\hline \multicolumn{5}{|l|}{ Residence } \\
\hline Urban & 637 & 89.6 & 1 & \\
\hline Rural & 2918 & 73.2 & $1.56(0.62-3.92)$ & 0.347 \\
\hline \multicolumn{5}{|l|}{ Wealth } \\
\hline Poorest & 799 & 61.6 & 1 & \\
\hline Poorer & 811 & 70.7 & $1.63(1.10,2.40)$ & 0.014 \\
\hline Middle & 693 & 78.7 & $2.23(1.47,3.39)$ & $<0.001$ \\
\hline Richer & 679 & 83.5 & $2.85(1.88,4.31)$ & $<0.001$ \\
\hline Richest & 575 & 92.0 & $5.30(2.51,11.19)$ & $<0.001$ \\
\hline \multicolumn{5}{|c|}{$\begin{array}{l}\text { Received information on HIV testing } \\
\text { during ANC }\end{array}$} \\
\hline No & 1519 & 56.7 & 1 & \\
\hline Yes & 2036 & 90.6 & $4.65(3.38,6.42)$ & $<0.001$ \\
\hline $\begin{array}{l}\text { Sexual behavior (lifetime } \\
\text { partners) }\end{array}$ & & & & \\
\hline 1 & 1679 & 72.4 & 1 & \\
\hline $2+$ & 1876 & 79.4 & $1.56(0.62,3.92)$ & 0.347 \\
\hline \multicolumn{5}{|c|}{ Stigmatizing attitudes towards HIV } \\
\hline No & 2556 & 72.9 & 1 & \\
\hline Yes & 999 & 84.3 & $1.29(0.95,1.76)$ & 0.103 \\
\hline \multicolumn{5}{|l|}{ Type of health facility } \\
\hline Hospital & 573 & 97.3 & 1 & \\
\hline Health centre & 181 & 95.4 & $0.71(0.24,2.15)$ & 0.546 \\
\hline Dispensary & 1639 & 94.8 & $0.69(0.31,1.56)$ & 0.375 \\
\hline 0 thers & 1163 & 36.3 & $0.02(0.01,0.05)$ & $<0.001$ \\
\hline
\end{tabular}

${ }^{\dagger}$ Results are adjusted for stigmatizing attitudes towards H IV, residence, sexual behavior (lifetime sexual partners) and type of health facility. 


\section{Discussion}

The analysis revealed that about three quarters of pregnant women going to antenatal clinic accessed HIV test (including receiving results) and will get the benefits of PMTCT, while a quarter who did not will not get the benefits of PMTCT. Several factors were found to be significantly associated with the testing for HIV among pregnant women attending antenatal clinic. Factors significantly associated with lower odds of HIV testing included young age of the pregnant mother and having primary or lower level of education. Those related with increased odds of HIV testing were higher wealth levels and having received HIV information during AN C.

Global technology response to the HIV epidemic was the development of ART which made HIV testing and collection of results a core strategy in the care and support for HIV and AIDS. However, the rollout of HIV testing and ART witnessed varying response to test uptake as well as going back for results which was observed to vary from less than $20 \%$ to $100 \%$ depending on the context (Shetty, Marangwanda et al. 2008; Tudor Car, Van Velthoven et al. 2012). In this study about a quarter of the pregnant women attending antenatal care did not test despite being in health care setup. To date still people like pregnant women fear to take results contributing significantly to the pool of those eligible but unable to access ART. Unwillingness to collect results has been observed to be due to fear of discrimination and self-stigmatization in anticipation of HIV positivity which is also likely to be the case among this population (Turan, Hatcher et al.; Turan, Miller et al. 2008).

Studies on stigma and health have reported that with high level of education attainment there is correspondingly low level of stigma ( $\mathrm{O} w$ and Lee 2012). Also this study revealed a significant association between education attained and HIV testing and collection of test results. The pathway through which these two are associated could be through existing society discrimination especially among those with low education develops selfstigmatization and consequently fear to collect results and in turn enhances self-discrimination and self-stigmatization. Studies done in other places have reported similar relationship between education and collection of results after testing even with the advent of rapid HIV test results (Veloso, Bastos et al. 2010). The findings notwithstanding, it could be wise to study in detail the relationship between low education and HIV testing in order to have better strategy that will increase the HIV test uptake.
The study found out that younger pregnant women were less likely to test and collect results compared to those who were older. Similar relationships are reported in Kenya in a study on knowledge of HIV status a major barrier to HIV prevention, care and treatment efforts where one can overcome stigma and discrimination (C herutich, Kaiser et al. 2012). It could also be an effect of ongoing community based interventions where older women have undergone longer exposures to HIV education leading to increased skills to overcome discrimination and stigma. Such information exposure enables one overcome the perceptions of risk as a result make a decision to go for the test. This statement is supported by the finding that those who had received HIV information during antenatal care had four times the odds of taking HIV test.

Another factor which increased odds of taking the HIV test was the household wealth, as household wealth increased the odds increased compared to the least wealthy. Similar relationship between HIV test and wealth has been reported in several studies (Ettenger, Barnighausen et al. 2013). Better wealth in a household could reflect more educated family members and because of better education they are more likely to make healthy decisions including taking a test such relationship has also been observed in U ganda(Ishmael Kalule-Sabiti, Acheampong Yaw Amoateng et al. 2014). On the other hand in such households they could be more supportive during AN C including husbands who will encourage uptake. In addition well-resourced households would also translate into better access to health services and assurance if one is found HIV positive, PMTCT care and effective interventions are available.

Study limitation

This study analyzed THMIS data which was collected for the purpose of highlighting survey indicators for HIV and Malaria. Because of that the independent variables are limited to what was available in the datasets. O nly associations and not causality between the dependent and independent variables can be assessed.

\section{Conclusions and Recommendations}

Just more than three quarters of the pregnant women attending antenatal care tested and collected the results for HIV and therefore enabling the eligibility to access ART. However, those who did not access HIV test increases the pool that shall contribute and sustain the burden of childhood HIV. Thus those who did not access HIV test during AN C 
is a significant proportion which this study found it could be due to young age, low education level, not receiving HIV information during ANC and poor household wealth.

The high proportion of the women attending antenatal care accessed HIV testing notwithstanding, strategies to increase access to information on testing during ANC should be enhanced while stressing the benefits to all and other relevant contexts. In addition such strategies should emphasize on those with low education, younger age and those least wealthy.

\section{Acknowledgment}

The team is very grateful to Measure DHS for allowing the use of the Tanzania DHS data :

\section{Authors contributions:}

1. Innocent A.Semali analyzed the data, wrote drafts of the manuscript, reviewed literature, edited and finalized the manuscript.

2. Damaian Jeremiah: compiled the data set, analyzed the data and edited the manuscript.

3. Happiness P. Saronga: reviewed literature, compiled the data set analyzed it and edited the manuscript

4. Deogratius Malamsha: compiled and analyzed the data, wrote the initial draft and edited the manuscript.

\section{References}

Cherutich, P., R. Kaiser, et al. (2012). "Lack of knowledge of HIV status a major barrier to HIV prevention, care and treatment efforts in Kenya: results from a nationally representative study." PLoS One 7(5): e36797.

Chi, B. H., M. R. Adler, et al. (2012). "Progress, challenges, and new opportunities for the prevention of mother-to-child transmission of HIV under the US President's Emergency Plan for AIDS Relief." $\perp$ Acquir Immune Defic Syndr 60 Suppl 3: S78-87.

Ettenger, A., T. Barnighausen, et al. (2013). "Health insurance for the poor decreases access to HIV testing in antenatal care: evidence of an unintended effect of health insurance reform in Colombia." Health Policy Plan.

Ezegbe, C. and N. Stephenson (2012). "The reach and limits of the US President's Emergency Plan for Aids Relief (PEPFAR) funding of Prevention of Mother-to-Child Transmission (PMTCT) of HIV in $\mathrm{N}$ igeria." Afr J Reprod Health 16(1): 23-34.

Ishmael Kalule-Sabiti, Acheampong Yaw Amoateng, et al. ( 2014). "The Effect of Socio-demographic
Factors on the Utilization of Maternal Health Care Services in Uganda." African Population Studies, 28 (1): 10.

Joshi, U., A. Kadri, et al. (2010). "Prevention of parent to child transmission services and interventions - coverage and utilization: A cohort analysis in Gujarat, India." Indian J Sex Transm Dis 31(2): 92-8.

Lozano, R., M. N aghavi, et al. (2012). "Global and regional mortality from 235 causes of death for 20 age groups in 1990 and 2010: a systematic analysis for the Global Burden of Disease Study 2010." Lancet 380(9859): 2095-128.

Lyons, C., A. Mushavi, et al. (2012). "Ending pediatric AIDS and achieving a generation born HIV-free." L Acquir Immune Defic Syndr $\mathbf{6 0}$

\section{Suppl 2: S35-8.}

Ministry of Health and Social Welfare (2012). Tanzania Elimination of Mother to Child Transmision of HIV Plan, 2012-2015 M. O. H. a. S. Welfare. Dar es Salaam U nited Republic of Tanzania Tanzania Mainland

Murray, C. J., T. Vos, et al. (2012). "Disabilityadjusted life years (DALYs) for 291 diseases and injuries in 21 regions, 1990-2010: a systematic analysis for the Global Burden of Disease Study 2010." Lancet 380(9859): 2197-223.

N yandiko, W. M., B. O tieno-N yunya, et al. (2010). "O utcomes of HIV-exposed children in western Kenya: efficacy of prevention of mother to child transmission in a resource-constrained setting." 1 Acquir Immune Defic Syndr 54(1): 42-50.

Ow, C. Y. and B. O. Lee (2012). "Relationships Between Perceived Stigma, Coping O rientations, Self-esteem, and Q uality of Life in Patients With Schizophrenia." Asia Pac J Public Health.

Paredes, R., V. C. Marconi, et al. (2013). "Impact of antiretroviral drugs in pregnant women and their children in Africa: HIV resistance and treatment outcomes." IInfect Dis 207 Suppl 2: S93-100.

Shetty, A. K., C. Marangwanda, et al. (2008). "The feasibility of preventing mother-to-child transmission of HIV using peer counselors in Zimbabwe." AIDS Res Ther 5: 17.

StataC orp. (2009). Stata Statistical Software: Release 9.0. . Texas, US: , Stata Corporation

Tanzania Commission for AIDS (TACAIDS), Zanzibar AIDS Commission (ZAC), et al. (2013). Tanzania HIV/AIDS and Malaria Indicator Survey 2011-12. Z. TACAIDS, NBS, OCGS, and ICF International. D ar es Salaam, T anzania TACAIDS, ZAC,N BS, O CGS, and ICF International. 
Tubiana, R., L. Mandelbrot, et al. (2013). "Lopinavir/Ritonavir Monotherapy as a $\mathrm{N}$ ucleoside Analogue-Sparing Strategy to Prevent HIV-1 Mother-to-Child Transmission: The AN RS 135 PRIMEVA Phase 2/3 Randomized Trial." Clin Infect Dis 57(6): 891-902.

Tudor Car, L., M. H. van-Velthoven, et al. (2011). "Integrating prevention of mother-to-child HIV transmission (PMTCT) programmes with other health services for preventing HIV infection and improving HIV outcomes in developing countries." Cochrane Database Syst $\operatorname{Rev}(6)$ : CD008741.

Tudor Car, L., M. H. Van Velthoven, et al. (2012). "Integrating prevention of mother-to-child HIV transmission programs to improve uptake: a systematic review." PLoS O ne 7(4): e35268.

Turan, J. M., A. H. Hatcher, et al. "The role of HIVrelated stigma in utilization of skilled childbirth services in rural Kenya: a prospective mixedmethods study." PLoS Med 9(8): e1001295.
Turan, J. M., S. Miller, et al. (2008). "HIV/AIDS and maternity care in Kenya: how fears of stigma and discrimination affect uptake and provision of labor and delivery services." AIDS Care 20(8): 938-45.

van Tienen, C., M. F. van der Loeff, et al. (2010). "HTLV-1 in rural Guinea-Bissau: prevalence, incidence and a continued association with HIV between 1990 and 2007." Retrovirology 7: 50.

Veloso, V. G., F. I. Bastos, et al. (2010). "HIV rapid testing as a key strategy for prevention of mother-to-child transmission in Brazil." $\underline{\text { Rev }}$ Saude Publica 44(5): 803-11.

Watson-Jones, D., R. Balira, et al. (2012). "Missed opportunities: poor linkage into ongoing care for HIV-positive pregnant women in Mwanza, Tanzania." PLoS O ne 7(7): e40091.

Wettstein, C., C. Mugglin, et al. (2012). "Missed opportunities to prevent mother-to-childtransmission: systematic review and metaanalysis." Aids 26(18): 2361-73. 